\title{
Occipital condyles and its relation with hypoglossal canal: Anatomical study in central Indian population
}

\author{
Naresh Thanduri ${ }^{1}$, Neha Rai ${ }^{2, *}$, Sheema Nair ${ }^{3}$, Vishal Bankwar ${ }^{4}$ \\ ${ }^{1}$ Assistant Professor, ${ }^{2}$ Associate Professor, ${ }^{3,4}$ Professor, ${ }^{1,2,3}$ Dept. of Anatomy, ${ }^{4}$ Dept. of Community Medicine, LN Medical \\ College and Hospital, Bhopal, Madhya Pradesh, India
}

*Corresponding Author:
Email: drneharai@gmail.com

Received: $23^{\text {rd }}$ February, 2018

Accepted: $27^{\text {th }}$ February, 2018

\begin{abstract}
Introduction: For transcondylar approach, most relevant step during surgical process is the resection of OC. Also it is important to have knowledge about it relevant anatomy and its relation with hypoglossal canal. This helps to avoid any iatrogenic injury during craniovertebral surgeries.

Aims: The present study helps us to understand the morphological and morphometric data of occipital condyles and its relation with hypoglossal canal and its importance in transcondylar approach.

Materials and Methods: The study was performed on 85 adult human dry skulls of unknown age and sex, obtained from Dept. of Anatomy, LNMC\& JK hospital, Bhopal, India. Manual vernier calliper was used for the measurement. The length of the OC was measured. Also its shape was noted. In addition to all this, the different location of hypoglossal canal in relation to OC were assessed.

Statistical Analysis: Mean and standard deviation of the parameters were analysed. Comparision was made of left and right side using unpaired t test and $\mathrm{p}$ value was calculated.

Percentage of location of hypoglossal canal was calculated in relation with occipital condyles.

Results: The mean of the length of occipital condyle on right side were found to be $21.24 \mathrm{~mm}$ and on left side $20.71 \mathrm{~mm}$. The most common shape was quadrilateral type. The most common location of intracranial orifice of hypoglossal canal was located at location 4 and extracranial orifice was detected at location 3.

Conclusion: All these parameters will be useful for performing various transcondylar surgical approaches and for reaching lesions in middle and posterior part of cranial base.
\end{abstract}

Keywords: Occipital condyles, Hypoglossal canal, Transcondylar approach, Morphometry.

\section{Introduction}

The posterior part of human skull is formed mainly by occipital bone. Adjoining the foramen magnum the occipital condyles are present. The occipital condyles are the distinctive bony structure linking the skull and vertebral column. ${ }^{1}$ The superior articular facets of the atlas articulates with the occipital condyles to form atlanto occipital joint. The occipital condyles are oval in shape and placed in an oblique manner so that its anterior end lies closer to the midline than its posterior end. ${ }^{2}$ Occipital condyles represent the cranial aspect of craniovertebral joint. The hypoglossal canal is directed anterolaterally and present above the occipital condyles at its junction of anterior $1 / 3$ and posterior $2 / 3$. It transmits the hypoglossal nerve, meningeal branch of ascending pharyngeal artery and emissary vein connecting basilar plexus to internal jugular vein. This venous plexues is highly important as it serves as major sources of venous drainage through posterior cranial fossa.

Extradural and intradural tumours are frequently seen in cranial base near foramen magnum and it posses a challenge to surgeons due to its deeper location. As the ventral approach is dangerous and has a high rate of morbidity the dorsal approach is mostly preferred at the CVJ. ${ }^{5,6}$

In modern era with advanced technology, transcondylar approach (TCA) has gained popularity which enables shorter and more direct route to anterior part of pontomedullary junction with minimal brainstem retraction. The key point of this surgery includes drilling of posterior part of OC which threatens opening of HC. ${ }^{7}$ The extent of bony removal for optional exposure is unclear ranging from suboccipital craniotomy to total $\mathrm{OC}$ remonal. ${ }^{8-10}$

The position of $\mathrm{HC}$ in relation to $\mathrm{OC}$ is very significantly for neurosurgeons. Very scanty information was available the shape of OC, its length and its relation with the $\mathrm{HC}$ in central Indian population. Hence, aim of present study was to analyse the shape of $\mathrm{OC}$, its length and portion of $\mathrm{HC}$ in respect to the OC in central Indian population.

\section{Materials and Methods}

In the present study, 85 adult human dry skulls of unknown age and sex were obtained from the Dept of Anatomy, LN Medical College and Research centre. Dry skulls those were in good condition were included 
in the study. Deformed, damaged and pathological skull were excluded from the study. Manual vernier calliper was used for the measurement.

Morphometric study:

A single following parameter was measured of 170 occipital condyles (i.e right and left side):

Length of the condyles: Largest antero-posterior distance between anterior and posterior tips of occipital condyles.

The parameters were measured by using manual vernier calliper. The measurements were repeatedly taken to ensure the accuracy. All the measurements were taken in $\mathrm{mm}$.

The data were statistically analysed and tested for significance between the right and left sides.

Table 1: Locations of the hypoglossal canal orifice relative to the occipital condyle

\begin{tabular}{|c|c|}
\hline Location & Position of the orifice relative to occipital condyle \\
\hline Location 1 & 1st one-fourth of occipital condyle \\
\hline Location 2 & $\begin{array}{l}\text { Junction of the } 1 \text { st and } 2 \text { nd one-fourth of occipital } \\
\text { condyle. }\end{array}$ \\
\hline Location 3 & $2^{\text {nd }}$ one - fourth of occipital condyle \\
\hline Location 4 & $\begin{array}{l}\text { Junction of } 2^{\text {nd }} \text { and } 3^{\text {rd }} \text { one fourth of occipital } \\
\text { condyle }\end{array}$ \\
\hline Location 5 & $3^{\text {rd }}$ one - fourth of occipital condyle \\
\hline Location 6 & $\begin{array}{l}\text { Junction of } 3^{\text {rd }} \text { and } 4^{\text {th }} \text { one fourth of occipital } \\
\text { condyle }\end{array}$ \\
\hline Location 7 & $4^{\text {th }}$ one - fourth of occipital condyle \\
\hline
\end{tabular}

\section{Statistical Analysis}

Unpaired t test results: The two tailed $\mathrm{P}$ value equal $0.6006 . \mathrm{By}$ conventional criteria, this difference is considered to be not statistically significant. Confidence Interval - Mean of left and right side is 0.53 . $95 \%$ Confidence interval of this difference from 1.51 to 2.57 .

\section{Results}

170 occipital condyles of 85 adult human dry skull were used for this study.

Morphometric study: The results obtained from the present morphological study is tabulated in TABLE 2. Mean length of the occipital condyle were found to be $21.24 \mathrm{~mm}$ on right and $20.71 \mathrm{~mm}$ on left side. The range of length was $16-26 \mathrm{~mm}$ on right side while it was $15-27 \mathrm{~mm}$ on left side $\mathrm{P}$ value is 0.6006 , this difference is considered to be not statistically significant.

Table 2: Comparison of Right and Left side of occipital condylar parameters

\begin{tabular}{|c|c|c|c|c|c|c|c|c|c|}
\hline S. No & Parameter & \multicolumn{3}{|c|}{ Right } & \multicolumn{3}{|c|}{ Left } & P value & Significance \\
\cline { 2 - 9 } & Mean & SD & $\begin{array}{l}\text { Range } \\
(\mathbf{m m})\end{array}$ & Mean & SD & Range & & $\begin{array}{c}\text { Unpaired } \\
\text { t test }\end{array}$ \\
\hline 1 & $\begin{array}{l}\text { Length of } \\
\text { occipital } \\
\text { condyles }\end{array}$ & 21.24 & 2.82 & $16-26$ & 20.71 & 3.02 & $15-27$ & 0.60 & $\begin{array}{l}\text { Not } \\
\text { significant }\end{array}$ \\
\hline
\end{tabular}

Morphological Study: In the present study occipital condyles were classified according to their shapes in 8 different types as shown TABLE 3 . The percentage of each was calculated and comparsion was made between right and left. The most common type was found to be quadrilateral type which is $23.52 \%$ in central Indian population. The most unusual type was kidney type i.e $8.8 \%$ and Ring like was absent. When the right and the left occipital condyles of the same skull were compared, then the most common type on right side (23.5\%) was quadrilateral and on left side it $(29.4 \%)$ was triangular. 
Table 3: The rate of different shapes of the occipital condyles

\begin{tabular}{|l|c|c|c|}
\hline \multicolumn{1}{|c|}{ Type } & Right & Left & Total \\
\hline 1 Kidney shaped & $11.7 \%$ & $5.8 \%$ & $8.8 \%$ \\
\hline 2. S- like & $17 \%$ & $11.2 \%$ & $14.5 \%$ \\
\hline 3.Oval & $17 \%$ & $5.8 \%$ & $11.7 \%$ \\
\hline 4.Two portioned & $17 \%$ & $11.7 \%$ & $14.7 \%$ \\
\hline 5. 8 -Shaped & $11.7 \%$ & $11.7 \%$ & $11.76 \%$ \\
\hline 6. Ring like & $0.0 \%$ & $0.0 \%$ & $0.0 \%$ \\
\hline 7. Triangular & $0.0 \%$ & $29.4 \%$ & $14.7 \%$ \\
\hline 8. Quadrilateral & $23.5 \%$ & $23.5 \%$ & $23.52 \%$ \\
\hline
\end{tabular}

In this study, the location of the intracranial and extracranial orifices of the hypoglossal canal in relation to the occipital condyles are tabulated in a Table $4 \& 5$ respectively.

It was found that the intracranial orifice of hypoglossal canal was found to present from location 2 to location 4. Out of which, most common location was found to be location 4 having $52.94 \%$ followed by location 3 having $47.05 \%$ in central Indian population. Location 2 has an extremely low percentage i.e $2.9 \%$. The intracranial orifice was not obtained in location 1, 5, 6 and 7.

Table 4: The location of intracranial orifices of hypoglossal canal relative to the occipital condyle

\begin{tabular}{|l|c|c|c|c|c|}
\hline \multirow{2}{*}{ Location } & \multicolumn{5}{|c|}{ Intracranial orifice } \\
\cline { 2 - 6 } & \multicolumn{2}{|c|}{ Right } & \multicolumn{2}{c|}{ Left } & Total \\
\cline { 2 - 6 } & Number & \% & Number & \% & \% \\
\hline Location 1 & 0.0 & 0.0 & 0.0 & 0.0 & 0.0 \\
\hline Location 2 & 1 & 5.8 & 0.0 & 0.0 & 2.9 \\
\hline Location 3 & 11 & 64.7 & 5 & 29.4 & 47.05 \\
\hline Location 4 & 6 & 35.29 & 12 & 70.58 & 52.94 \\
\hline Location 5 & 0.0 & 0.0 & 0.0 & 0.0 & 0.0 \\
\hline Location 6 & 0.0 & 0.0 & 0.0 & 0.0 & 0.0 \\
\hline Location 7 & 0.0 & 0.0 & 0.0 & 0.0 & 0.0 \\
\hline
\end{tabular}

While, extracranial orifice of hypoglossal canal was found to present from location 1 to location 4 . Out of which, most common location was location 3 having $35.29 \%$ followed by location 2 having $32.35 \%$ in central Indian population. Location 1 has $26.4 \%$ and least percentage is of location 4 . The extracranial orifice was not found at location 5, 6 and 7 .

Table 5: The location of extracranial orifices of hypoglossal canal relative to the occipital condyle

\begin{tabular}{|l|c|c|c|c|c|}
\hline \multirow{2}{*}{ Location } & \multicolumn{5}{|c|}{ Extracranial orifice } \\
\cline { 2 - 6 } & \multicolumn{2}{|c|}{ Right } & \multicolumn{2}{c|}{ Left } & Total \\
\cline { 2 - 6 } & Number & \% & Number & \% & \% \\
\hline Location1 & 2 & 11.76 & 7 & 41.17 & 26.4 \\
\hline Location2 & 4 & 23.52 & 7 & 41.17 & 32.35 \\
\hline Location3 & 11 & 67.7 & 1 & 5.8 & 35.29 \\
\hline Location4 & 0.0 & 0.0 & 2 & 11.76 & 5.8 \\
\hline Location5 & 0.0 & 0.0 & 0.0 & 0.0 & 0.0 \\
\hline Location6 & 0.0 & 0.0 & 0.0 & 0.0 & 0.0 \\
\hline Location7 & 0.0 & 0.0 & 0.0 & 0.0 & 0.0 \\
\hline
\end{tabular}


Fig. 1: "Triangle type" occipital condyles
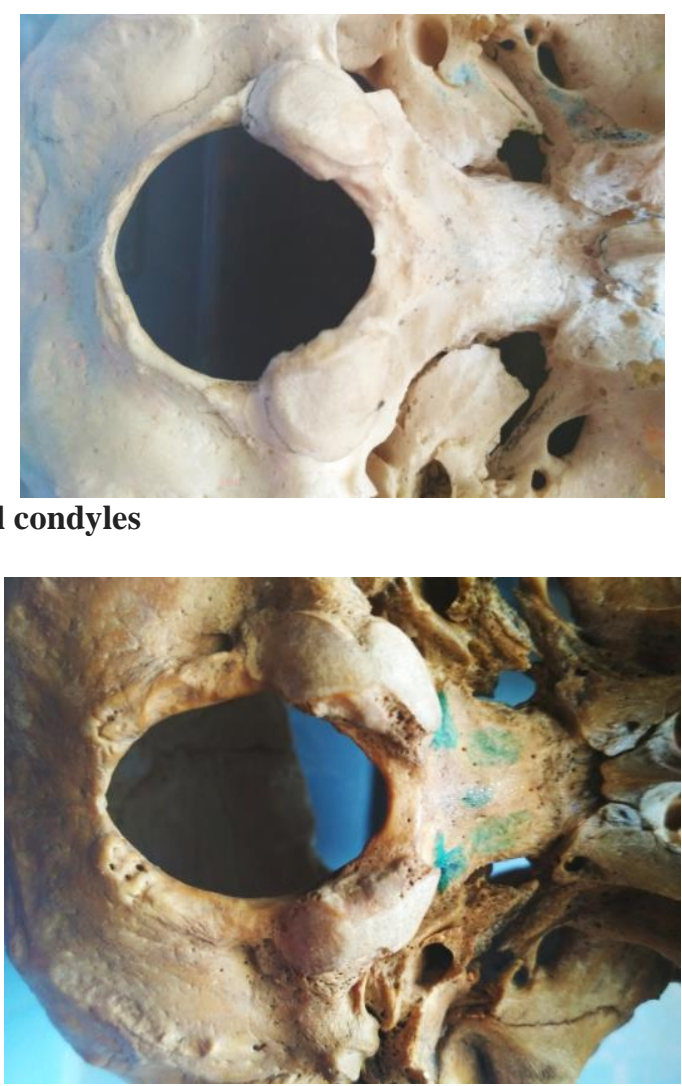

Fig 2: 8 type of Occipital condyles

\section{Discussion}

Variations of craniovertebral junctions are of interest not only to the anatomist but also to the clinicians because of various surgical approaches, like transcondylar, partial transcondylar approach, occipital condyle resection (partial / complete ) used for posterior cranial fossa lesions. ${ }^{11,12}$

The length of occipital condyles is an important surgical issue. The results of partial condylectomy in short type are different from results obtained in long type occipital condyles. In case of shorter occipital condyles removal of $>$ $2 / 3$ part can lead to craniocervical instability. ${ }^{13}$ Various studies were done on length of occipital condyles. Length of occipital condyles was found to be larger in left side in studies of S. Kavita et. al, Aric et al, Archana K. Tale but length of occipital condyles was larger in right side at Diva mahajan et al, Mustafa bozuge et al, Naderi et al. ${ }^{1}$ In the present study also length of right occipital condyle was found to be larger than left i.e $21.24>20.34 \mathrm{~mm}$. The range of occipital condyle length on right side was $(16-26 \mathrm{~mm})$ and on the left side $(15-27 \mathrm{~mm})$ which was in accordance with the studies of Saliya et al. ${ }^{14}$

Table: 6 Comparison between other studies

\begin{tabular}{|l|c|c|c|c|c|c|c|c|c|}
\hline \multicolumn{2}{|c|}{ Parameter } & $\begin{array}{c}\text { S.Kavitha } \\
\text { et al (19) } \\
(\mathbf{2 0 1 3 )}\end{array}$ & $\begin{array}{c}\text { Divya } \\
\text { Mahajan } \\
\text { et al (20) } \\
\mathbf{( 2 0 1 1 )}\end{array}$ & $\begin{array}{c}\text { Mustafa } \\
\text { Bozbuga } \\
\text { et al (21) } \\
(\mathbf{1 9 9 9 )}\end{array}$ & $\begin{array}{c}\text { Avic } \\
\text { et al(22) } \\
\mathbf{( 2 0 1 1 )}\end{array}$ & $\begin{array}{c}\text { Naderi } \\
\text { et al(1) } \\
\mathbf{( 2 0 0 5 )}\end{array}$ & $\begin{array}{c}\text { Anil } \\
\text { Kumar } \\
\text { et al } \\
\mathbf{( 2 3 )} \\
\mathbf{( 2 0 1 4 )}\end{array}$ & $\begin{array}{c}\text { Bayat P } \\
\text { et al (24) } \\
\mathbf{( 2 0 1 4 )}\end{array}$ & Present study \\
\hline $\begin{array}{l}\text { Length } \\
\text { of } \\
\text { OC }\end{array}$ & R & 21.97 & 22.61 & 23.1 & 23.7 & 23.6 & - & 21.83 & 21.24 \\
\cline { 2 - 10 } & L & 22.34 & 22.36 & 22.9 & 24 & 23.2 & - & 22.19 & 20.71 \\
\hline
\end{tabular}

$\mathrm{Oc}=$ occipital condyle, $\mathrm{R}=$ right, $\mathrm{L}=$ left

The shape of occipital condyles decides the amount of condylectomy. Triangular, deformed and kidney type of occipital condyle requires a more extensive condylar resection. The nail resection becomes more easy in oval type of occipital condyle as compared to triangular, ring

like and two positioned type of occipital condyle. ${ }^{15}$ In our study on central Indian population overall most common type of occipital condyle was quadrilateral type $(23.52 \%)$, and on right side also quadrilateral type dominated by $(23.5 \%)$ as compared to other types. But on the left side triangular shape was predominated 
found $(29.4 \%)$. In contrast to our study Naderi et al (2005) found the most common shape of occipital condyle to be oval in greek population. Natsis et al (2013) in his study on greek population found oval type of occipital condyle right side (8.6\%) and on left side $(6.5 \%)$. Kalthur et al also noted oval type was the most common shape but with a frequency less than North Indian population. ${ }^{12}$ These finding suggests that North Indian and Greeks are at less risk of condylectomy as compared to Central Indian population due to triangular and quadrangular shape of occipital condyles are more prone to risks of condylectomy. ${ }^{16}$

The location of extracranial and intracranial openings of hypoglossal canal affects the lateral approaches to the cranialvertebral junction. This measurement gives an indication about the maximum amount of resectable condyle without entering the hypoglossal canal. ${ }^{17}$ In the present study the intracranial opening was found to be located on location $3>>$ in right side while on left side location $4>>3$ was more commonly found. The overall location was $4>>3>>2$. The location 1, 5, 6, 7 were not encountered where as Naderi et al reported intracranial opening in location 4 in more than $55 \%{ }^{1}$ Fetout FA et al in his study on Arab population found intracranial opening in 4 and 5 location with a total percentage of $65 \% .^{9}$

In present study extracranial opening of hypoglossal canal was found maximum on $3^{\text {rd }}$ location on right side whereas it was found to be on 1 and $2 \mathrm{rd}$ location on left. Overall the predominant location of extracranial opening of hypoglossal canal was $3>>2>>1>>4$. In accordance to our study on left side portion of extracranial opening of hypoglossal canal Naderie et al also found more than $90 \%$ location as 1 and 2. ${ }^{1}$ Fetout FA et al found extracranial opening of hypoglossal canal mainly in 2 and 3 locations with total $\%$ of $69 \%$ which was in accordance with our right side condylar study. ${ }^{18}$

\section{Conclusion}

The present study on central Indian population showed that:

1. The length of occipital condyle on right side was $(16-26 \mathrm{~mm})$ while on the left side $(15-27 \mathrm{~mm})$ with mean on right side (21 .24) and left side (20.71).

2. The overall shape of occipital condyle showed following trend as quadrilateral $>$ triangular $=\mathrm{S}$ shaped $=2$ positioned $>$ oval $=8$ shaped $>$ kidney shaped.

3. The overall position of hypoglossal canal intracranially was location $4>>3>>2$ while extracranially $3>>2>>1>>4$.

The above parameters will be useful for performing various transcondylar surgical neurosurgeon approaches and for reaching lesions in middle and posterior part of cranial base.

\section{References}

1. 1.Naderi S, Korman E, Çıtak G, Güvençer M, Arman C, Senoğlu M, et al. Morphometric analysis of human occipital condyle. Clin Neurol Neurosurg. 2005;107(3):191-99.

2. Susan Standring. Gray's Anatomy, 40th Edition. Anatomical basis of clinical practice, Churchill Livingstone, London. 2008;40:415.

3. DeGusta D, Gilbert WH, Turner SP. Hypoglossal canal size and hominid speech. [1] Proc Natl Acad Sci USA. 1999;96(4):1800-04.

4. Standring S, Editor. Gray's Anatomy: The Anatomical Basis of Clinical Practice. [2] 40th ed. Scotland: Churchill Livingstone Elsevier; 2008.

5. Al-Mefty O, Borba LA, Aoki N, Angtuaco E, Pait TG. The transcondylar approach to extradural nonneoplastic lesions of the craniovertebral junction. J Neurosurg 1996;84:1-6.

6. Wen HT, Rhoton AL Jr, Katsuta T, de Oliveira E. Microsurgical anatomy of the transcondylar, supracondylar, and paracondylar extensions of the farlateral approach. J Neurosur1997;87:555-85.

7. Wen HT, RhotonJr AL, Katsuta T, de Oliveira E. Microsurgical anatomy of the transcondylar, supracondylar and paracondylar extensions of the farlateral approach. J Neurosurg. 1997;87(4):555-85.

8. George B, Dematons C, Cophignon J. Lateral approach to the anterior portion of the foramen magnum. Application to surgical removal of 14 benign tumors : technical note. Surg Neurol 1988; 489- 90.

9. Bertalanffy H, Seeger W. The dorsolateral, suboccipital, transcondylar approach to the lower clivus and anterior portion of the craniocervical junction. Neurosurgery 1991;29:815-21.

10. Tedeschi H,Rhoton AL Jr. Lateral approaches to the petroclival region. Surg Neurol 1994;41:180-216.

11. Cross J, Coles A. Suppliers of advanced neuro embolization coils. Adv Clin Neurosci Rehabil.2002;2: 16-7.

12. 12.Kalthur SG, Padmashali S, Gupta C, and Dsouza AS. Anatomic study of the occipital condyle and its surgical implications in transcondylar approach. $\mathrm{J}$ craniovertebr junction spine .2014 Jun;5(2):71- 7.

13. 13.Barut N, Kale A, Turan Suslu H, Ozturk A, Bozbuga M, Sahinoglu K. Evaluation of the bony landmarks in transcondylar approach. Br J Neurosurg. 2009;23:276-81.

14. Muthukumar N, Swaminathan R, Venkatesh G, Bhanumathy SP. A morphometric analysis of the foramen magnum region as it relates to the transcondylar approach. Acta Neurochir 2005;147:889-95.

15. Ozer MA, Celik S, Govsa F, Ulusoy MO. Anatomical determination of a safe entry point for occipital condyle screw using three-dimensional landmarks. Eur Spine J. 2011;20:1510-7.

16. Verma R, Kumar S, Rai AM, Mansoor I, Mehra RD. The anatomical perspective of human occipital condyle in relation to the hypoglossal canal, condylar canal, and jugular foramen and its surgical significance. Journal of Craniovertebral Junction \& Spine. 2016;7(4):243-9.

17. Kumar S, Verma R, Rai AM, Mehra RD. Morphological and Morphometric Analysis of Hypoglossal Canal in North Indian Dry Skulls and It's Significance in Cranial Base Surgeries. Journal of Clinical and Diagnostic Research : JCDR. 2017;11(3):8-12. 
18. Fetouh FA, Awadalla AM. Morphometric analysis of the occipital condyle and its surgical implications in transcondylar approach. Skull Base.2009;19(03):23.

19. Kavitha S, Chandrasekaran S, Anand A, Shanthi KC Morphometric Study of Occipital Condyles in Adult Human Skulls. Int J Cur Res Rev, Aug 2013;05(15).

20. Archana K. Tale, Pratima R. Kulkarni, Sanobar Ismtulla Shaikh, Santosh S. Fupare. MORPHOMETRIC STUDY OF THE OCCIPITAL CONDYLE AND ITS SURGICAL IMPORTANCE. Int J Anat Res 2016;4(1):1802-5.

21. Bozbuga M, Ozturk A, Bayraktar B, Ari Z, Sahinoglu K, Polat G, et al. Surgical anatomy and morphometric analysis of the occipital condyles and foramen magnum. Okajimas Folia Anat Jpn 1999;75:329-34.

22. 22.Avic E, Dagtekin A, Ozturk A.H, Kara.E, Ozturk NC, Uluc $\mathrm{K}$ et.al. Anatomical variations of the foramen magnum, occipital condyle and jugular tubercle. Turk Neurosurg 2011; 21(2):181-90.

23. Kumar A and Nagar M. Human Adult Occipital Condyles: A Morphometric Analysis. RRJMHS, 2014;3(4);112-6.

24. Bayat P, Bagheri M, Ghanbari A, \& Raoofi A.

Characterization of occipital condyle and comparison of its dimensions with head and foramen magnum circumferences in dry skulls of Iran.Int JMorphol :444448, 2014. 